\title{
Biochemical Defenses Induced by Mycorrhizae Fungi Glomus Mosseae in Controlling Strawberry Fusarium Wilt
}

\author{
Wang Yanan ${ }^{1,2}$, Zhao Xusheng ${ }^{1,2}$, Yin Baozhong ${ }^{1,2}$, Zhen Wenchao ${ }^{1,2^{*}, *}$ and Guo Jintang ${ }^{3}$ \\ ${ }^{I}$ College of Plant Protection, Agricultural University of Hebei, No. 289 Lingyusi Street, Baoding City, 071001, Hebei, \\ China; ${ }^{2}$ Research Center for Biocontrol Techniques against Pests on Crops of Hebei Province, No. 289 Lingyusi Street, \\ Baoding City, 071001, Hebei, China; ${ }^{3}$ Mountainous Areas Research Institute of Hebei, No. 289 Lingyusi Street, Baoding \\ City, 071001, Hebei, China
}

\begin{abstract}
The effect of VAM on reducing wilt caused by Fusarium oxysporum Schlecht. f.sp. fragariae Winks et Williams (FO) infection in strawberry and the possible mechanisms involved were investigated. Two key substances involved in disease defenses, lignin and hydroxyproline-rich glycoprotein were induced and formed in the cell wall of strawberry root, and the peak content of lignin and hydroxyproline-rich glycoprotein was obtained on the 25 th day $(149.52 \mathrm{mg} / \mathrm{g})$ and on the 15 th day $(10.08 \mathrm{mg} / \mathrm{g})$, respectively. The activity of protective enzymes SOD, POD and CAT inoculation with VAM significantly increased when compared with the control under both CK (natural growth) and inoculated with FO. The conductivity of VAM plus FO treatment was higher than the CK treatment, but significantly lower than the FO treatment.
\end{abstract}

Keywords: Fusarium wilt, Inhibitory mechanism, Mycorrhizae fungi, Strawberry, Arbuscular Mycorrhiza.

\section{INTRODUCTION}

Strawberry, Fragriae ananassa Duch., belongs to the Rosaceae family and is the first fruit in the world ranking of small berry production. It is common that cultivators practice continuous harvesting of strawberry in China because of limited arable land and protective production frequently adopted; but with the increase of cultivation period, many problems such as soil salinity, soil acidification, nutrient imbalance and soil biological degradation have been found. Among these problems, soilborne diseases, especially Fusarium oxysporum Schlecht. f.sp. fragariae Winks et Williams (strawberry Fusarium Wilt, SFW) which manifests in strawberry and results in plant wilt, have been particularly serious in strawberry production $[1,2]$. The incidence of SFW was observed to be $90 \%$ and $100 \%$ when the strawberry plant was grown at the second and the third year, respectively in Hebei area; while losses owing to SFW reached $10 \%-15 \%$ in the second year, $20 \%-25 \%$ in the third year and more than $40 \%$ in the fourth year where the strawberry was replanted.

Mycorrhizae are mutualistic associations between plant roots and fungi. These beneficial symbioses are ubiquitous in nature and almost all plant species have some form of mycorrhizal association with fungi [3].

Mycorrhizae can provide a crucial link between plants and the surrounding soil environment, which leads to many direct and indirect benefits to plant communities. These fungi can help the plant gain better nutrition, enhance drought, resistance and so on. Among these benefits, the best recognized of which is the enhancement of resistance [4].

*Address correspondence to this author at the Research Center for Biocontrol Techniques against Pests on Crops of Hebei Province, No. 289 Lingyusi Street, Baoding City, 071001, Hebei, China; Tel: +86-13582903299;

E-mail: 13582903299Wenchao@qq.com
Vesicular Arbuscular Mycorrhiza (VAM), as the most popular endomycorrhizae, is a kind of mycorrhizae whose hyphae penetrate the cells of plant roots, producing structures that are either balloon like (vesicles) or dichotomously branching invaginations (arbuscules).

Mycorrhizal fungi may increase the resistance of plants to diseases through the following mechanisms, (1) improvement of plant nutrient status; (2) competition; (3) changed roots morphology and structure; (4) changed microbialflora in rhizosphere; (5) induced resistance or systematic resistance in plant (Huang, Jinhua, et al., 2003). However, few studies have considered whether mycorrhizae could change the contents of structural material or protective enzyme.

The objective of this study was to observe the induction of physiological changes in the strawberry associated with disease inhibition in a pots culture assay by mycorrhizae Glomus mosseae in order to provide a theoretical basis and technical support for further analysis to reduce continuous obstacles in the production of strawberry.

\section{MATERIALS AND METHODS}

\subsection{Materials}

The Glomus Mosseae (GM), was obtained from the collection preserved at the Institute of Plant Nutrition and Resources, Beijing Academy of Agriculture and Forestry Sciences, China. Fusarium oxysporum Schlecht. f.sp. fragariae Winks et Williams was provided by the laboratory of Plant Disease Ecology, Agricultural University of Hebei, China. The strawberry (F. ananassa Duch.) in this experiment is cultivar 'Totonka'.

\subsection{Pre-treatment}

The seedlings of strawberry 'Totonka' with consistent growth were selected to be planted in nutrition bowls that were disinfected by potassium permanganate and contained 
sterilized matrix, which was the mixture of perlite and vermiculite in a ratio of $1: 1$. Fifteen-day-old strawberry was used for all the experiments. Conidia suspension of F. oxysporum f.sp.fragariae was adjusted to $3 \times 10^{6}$ conidia $/ \mathrm{mL}$ with sterile distilled water.

Thirty strawberry plants were inoculated with $30 \mathrm{~mL}$ G. mosseae in the soil (G.m, about 15000 inoculum potential units), the other 30 plants representing the non-inoculated controls were grown naturally. To evaluate the presence of G. mosseae in strawberry plants, roots in the pots, some days after their inoculation, were sampled from inoculum site and surveyed by means of acid fuchsin stain after the roots were lysised in alkaline solution. When infection rate in strawberry roots was more than $90 \%$ after inoculation with G. mosseae, a standard size drop $(5 \mathrm{ml})$ of conidial suspension of the pathogen was placed around the roots of individual plant. Control plants (CK) were inoculated only with an equal amount of sterile distilled water and each treatment was repeated twice. The status of $\mathrm{F}$. oxysporum f.sp.fragariae of strawberry plants growing in the pots was also assessed by means of acid fuchsin stain, and when the infection rate of the pathogen in roots was more than $90 \%$. The roots of strawberry plant were taken as a sample at 5 days' intervals for further study.

\subsection{Content of Lignin and Hydroxyproline-rich Glycoprotein}

Lignin was determined by the ash -free residue by the two-stage $\mathrm{H}_{2} \mathrm{SO}_{4}$ hydrolysis (Huang, Jinhua, et al., 2003). The hydroxyproline-rich glycoprotein (HRGP) was determined according to Kivirikko (Kivirikko K. I.,1967).

\subsection{Analysis of Protective Enzymes Activity}

Peroxidase (POD) activity was determined by measuring the increase in absorption at $470 \mathrm{~nm}$ according to Kalir et al. (1984) with modification. Catalase (CAT) activity was determined by monitoring the decomposition of $\mathrm{H} 2 \mathrm{O} 2$ at 240 $\mathrm{nm}$ following the method of Aebi (1984). Superoxide Dismutase (SOD) activity was performed according to the description by Cakamsh and Marschner (1992).

To measure the electric conductivity, 30 roots sampled from each plant were put into a tube containing $10 \mathrm{ml}$ distilled water and shaken for $12 \mathrm{~h}$ at $180 \mathrm{rpm}$. Following this, DDS-11A conductivity meter was used to measure it.

The data were analyzed by data processing system 7.05 (DPS7.05). Means were compared with Duncan's new multiple range method test. All statistical analyses were done at $\mathrm{p}=0.05$.

\section{RESULTS AND ANALYSIS}

\subsection{Effect of VAM G. Mosseae on Content of Lignin in Strawberry Plants}

The change in the content of lignin is an important index to determine the structural change of root cell walls. If the content lignin of plant roots increases, it indicates that the root cell walls get thick, lignified, and form barriers to defense pathogen invasion.
The content of lignin in strawberry showed a reduction after inoculation with $F$. oxysporum f.sp.fragariae for 5 days in AM and non-AM plants; however, in mycorrhizal plants, higher lignin content was observed in comparison with nonAM plants (Fig. 1). The content of lignin increased gradually after inoculating the pathogen, and the maximum content of lignin was obtained on the $25^{\text {th }}$ day $(149.52 \mathrm{mg} / \mathrm{g})$. The increment in the F. oxysporum f.sp.fragariae plus G. mosseae treatment was much higher than others.

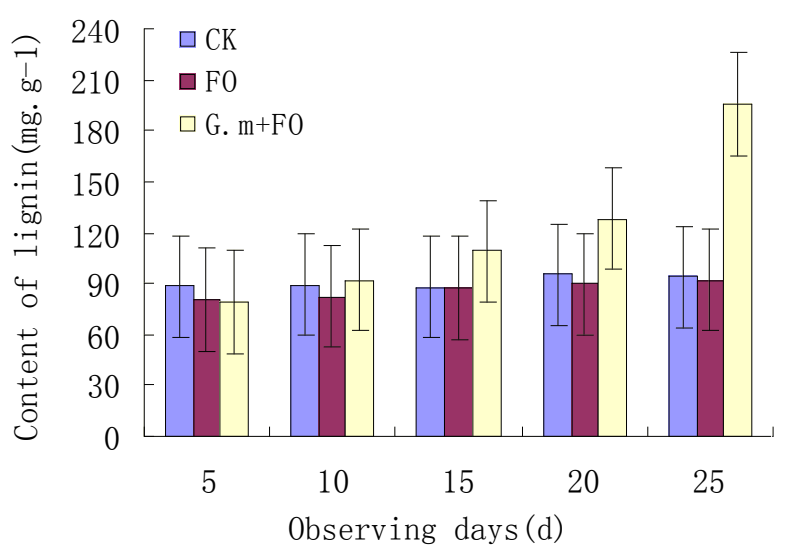

Fig. (1). Effect of VAM on lignin content in strawberry roots at 5day intervals after the inoculation of Fusarium oxysporum Schlecht. f.sp. fragariae.

\subsection{Effect of VAM G. Mosseae on Content of HRGP in Strawberry Plants}

HRGP is the major structural protein of plant cell walls, and is closely related with the formation of lignin. When the plant pathogen attacks or cell wall is damaged, large amounts of HRGP accumulate in plant to fix the damaged structure of the cell wall, thus enhancing disease resistance of plant.

Fig. (2) illustrates the changes in HRGP content of VAM- treated and non-treated strawberry roots at 5 days' intervals after the inoculation of Fusarium oxysporumSchl.f.sp. fragariae. The content of HRGP in strawberry roots with no-treatment was basically stable. However, the content of HRGP in strawberry roots decreased gradually after the pathogen inoculated and was $10.08 \mathrm{mg} / \mathrm{g}$ on the $250^{\text {th }}$ day after inoculation. Additionally, the application of VAM significantly increased the content of HRGP when compared with the control under both $\mathrm{CK}$ and $\mathrm{FO}$ conditions (Fig. 2).

\subsection{Effect of VAM Treatment on Activities of SOD, POD and CAT in Strawberry Plants}

Lipid peroxidation and large amounts of superoxide radicals producing in plants were usually caused by invasions by pathogens. The protective enzymes, for examples SOD, POD and CAT protect the cell through eliminating superoxide radicals. In addition, protective enzyme POD could catalyze cross-linking effects of glycoproteins which are rich in hydroxyproline of the cell wall in plants, thus cell wall can be strengthened, and blocking the intrusion of pathogens directly. 
Table 1. Changes in SOD, CAT, and POD activities of MGY2-treated and non-treated strawberry roots at different time intervals after the inoculation of Fusarium oxysporum Schlecht. f.sp. fragariae.

\begin{tabular}{|c|c|c|c|c|c|c|}
\hline \multirow{2}{*}{ Item } & \multirow{2}{*}{ Treatment } & \multicolumn{5}{|c|}{ Days After Inculation (d) (ug/g.FW) } \\
\cline { 3 - 7 } & & $\mathbf{5}$ & $\mathbf{1 0}$ & $\mathbf{1 5}$ & $\mathbf{2 0}$ & 25 \\
\hline \hline & CK & $29.47 \mathrm{~b}$ & $22.47 \mathrm{~b}$ & $21.27 \mathrm{~b}$ & $27.39 \mathrm{~b}$ & $20.14 \mathrm{~b}$ \\
\hline SOD & FO & $35.14 \mathrm{a}$ & $20.27 \mathrm{~b}$ & $18.17 \mathrm{ab}$ & $15.27 \mathrm{c}$ & $14.08 \mathrm{c}$ \\
\hline & G.m+FO & $30.17 \mathrm{~b}$ & $34.58 \mathrm{a}$ & $40.22 \mathrm{a}$ & $38.05 \mathrm{a}$ & $30.47 \mathrm{a}$ \\
\hline & CK & $231.24 \mathrm{a}$ & $214.22 \mathrm{~b}$ & $213.22 \mathrm{~b}$ & $228.74 \mathrm{~b}$ & $209.47 \mathrm{~b}$ \\
\hline POD & FO & $239.47 \mathrm{a}$ & $203.84 \mathrm{~b}$ & $187.49 \mathrm{c}$ & $166.71 \mathrm{c}$ & $140.22 \mathrm{c}$ \\
\hline & G.m+FO & $234.87 \mathrm{a}$ & $254.18 \mathrm{a}$ & $358.79 \mathrm{a}$ & $332.45 \mathrm{a}$ & $298.79 \mathrm{a}$ \\
\hline & CK & $200.14 \mathrm{a}$ & $197.42 \mathrm{c}$ & $195.24 \mathrm{~b}$ & $195.78 \mathrm{~b}$ & $199.47 \mathrm{~b}$ \\
\hline CAT & FO & $211.35 \mathrm{a}$ & $285.26 \mathrm{~b}$ & $149.36 \mathrm{c}$ & $124.98 \mathrm{c}$ & $89.74 \mathrm{c}$ \\
\hline
\end{tabular}

Table 2. Changes in of MGY2-treated and non-treated strawberry roots at different time intervals after the inoculation of Fusarium oxysporum Schlecht. f.sp. fragariae.

\begin{tabular}{|c|c|c|c|c|c|}
\hline \multirow{2}{*}{ Treatment } & \multicolumn{5}{|c|}{ Days After Inoculation (d) } \\
\cline { 2 - 6 } & $\mathbf{5}$ & $\mathbf{1 0}$ & $\mathbf{1 5}$ & $\mathbf{2 0}$ & $\mathbf{2 5}$ \\
\hline \hline CK & $37.26 \mathrm{c}$ & $37.75 \mathrm{c}$ & $43.36 \mathrm{c}$ & $89.52 \mathrm{c}$ & $37.73 \mathrm{c}$ \\
\hline FO & $69.45 \mathrm{a}$ & $70.01 \mathrm{a}$ & $84.66 \mathrm{a}$ & $58.87 \mathrm{~b}$ & $60.90 \mathrm{a}$ \\
\hline G.m+FO & $48.99 \mathrm{~b}$ & $51.90 \mathrm{~b}$ & $59.69 \mathrm{~b}$ & $61.53 \mathrm{~b}$ \\
\hline
\end{tabular}

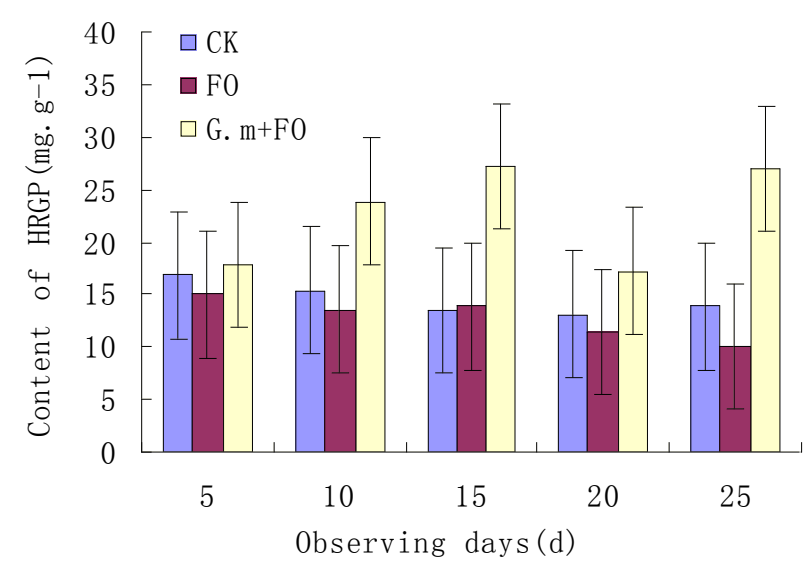

Fig. (2). Effect of VAM on HRGP in strawberry roots at different time intervals after the inoculation of Fusarium oxysporum Schlecht. f.sp. fragariae.

The activities of SOD, POD and CAT of strawberry roots were relatively stable under natural condition, but brought changes in the pathogen when the pathogen was attacked with varying the degrees of change. Among these changes, the maximum activity of SOD and POD was observed on the $5^{\text {th }}$ day after inoculation, and of CAT on the $10^{\text {th }}$ day.
The activity of protective enzymes SOD and POD was observed on the $10^{\text {th }}$ day after inoculated with VAM G. mosseae, which was shown later than FO treatment. The peak activities of SOD and CAT were observed on the $15^{\text {th }}$ day and $10^{\text {th }}$ day after inoculation. Additionally, the application of VAM significantly increased the activities of those protective enzymes when compared with the control under both CK and FO conditions (Table 1).

The electric conductivity of the plants is an important indicator for reflecting the reaction of peroxidation in cell membrane. Higher conductivity affects the structure of the cell membrane that would result in damaging cell membrane and interfering in normal physiological metabolism of the plant.

The electric conductivity of strawberry roots was observed to be relatively lower and stable under natural condition, but it sharply increased after inoculation with pathogens (Table 2). It was $90.9 \%$ on the $25^{\text {th }}$ day after inoculation. Inoculation with VAM fungi reduced the extent of increment in the electrical conductivity induced by pathogen infection. The conductivity of G.m plus FO treatment was higher than the CK treatment, but significantly lower than the FO treatment. 


\section{CONCLUSION}

VAM, which form symbiotic associations with the host roots, could involve in various physiological and biochemical metabolisms. Many researchers have focused on analyzing resistances to diseases induced by VAM among these effects, but its specific mechanism has not been properly studied. It is well-known that lignification of cell wall in the host plant is a resistant response in plant-pathogen association. Previous studies have shown that mycorrhizal fungi could induce certain metabolic processes to enhance lignification of the plant cell and make the cell wall thick; consequently, making the host plant form mechanical barriers defensing pathogen invasions. The distinct defense responses against Phytophthora parasitica have been observed during bio-protection induced by arbuscular mycorrhiza G. mosseae in tomato. The present study demonstrated that the VAM treatment induced changes in lignin and HRGP contents of the strawberry roots and these change enhanced resistance of roots by elicitation of host wall thickenings.

Once pathogens or viruses attack plants, exclusive defense systems of plants get be activated. Parts of defense systems induced by VAM fungi on the host might defense against the re-invasion of pathogens. Previous researches have shown that VAM enhance protective enzyme activities to scavenge oxidative stresses formed by the invasion of pathogens and prevent the plant cells from acute damages (Huang, Jinhua, et al., 2003; Yin, Baozhong, et al., 2009; Chen Shaoyu, 1991; Hu Jinli, et al., 2011). In this paper, SOD, POD and CAT activity was observed to significantly increase since 10-day after VAM inoculation. The fact that the elevated SOD, POD and CAT activity was associated with induced resistance by VAM G. mosseae provides a biochemical marker for further studies on pathogen-plant interactions.
Changes in electric conductivity of the outer exudates reflect changes in the cell membrane permeability and the extent of the damages. Under stress, peroxidation of cell membrane lipid increases, leading to excessive accumulation of free radicals which lead to the destruction of the membrane structure. The effect of VAM on the electric conductivity of the plants under the stresses has been demonstrated in several studies (Zou Qi, 2000). Electrical conductivity of strawberry roots reduced after inoculation with VAM G. mosseae (Gu, Xiangyang and $\mathrm{Hu}$, Zhengjia, 1994) while both cell membrane permeability and the exudates in cotton roots reduced after inoculation with VAM fungi. The similar result were observed in strawberry after inoculation with VAM in this paper.

\section{CONFLICT OF INTEREST}

The authors confirm that this article content has no conflict of interest.

\section{ACKNOWLEDGEMENTS}

This research was supported by the Nature Science Foundation of Hebei College for Youth (No. 2011152).

\section{REFERENCES}

[1] Y. Li, and C. Huang, "Influence of sports self-concept and selfefficacy on sports practice of university students," Journal of Sports Adult Education, vol. 27, no. 6, pp. 32-35, 2011.

[2] J. Liu, "Comparative research on difference between body shape and function and physical fitness of college students for differen body-mass index level," Journal of Pla Institute of Physical Education, vol. 30, no. 1, pp. 125-128, 2011.

[3] J. Ning, "Study of transformation of college students' exercise methods," Bulletin of Sport Science \& Technology, vol. 21, no. 4, pp. 85-87, 2013.

[4] D. Shi, and G. Yang, "Study on physical characteristics and influencing factors of fat students with difference physical exercise," Journal of Hubei Sports Science, vol. 32, no. 3, pp. 215-217, 2013.

Received: May 26, 2015

Revised: July 14, 2015

Accepted: August 10, 2015

(C) Yanan et al.; Licensee Bentham Open.

This is an open access article licensed under the terms of the (https://creativecommons.org/licenses/by/4.0/legalcode), which permits unrestricted, noncommercial use, distribution and reproduction in any medium, provided the work is properly cited. 